\title{
Subsidence after Anterior Cervical Interbody Fusion Using a Zero-Profile Device
}

\author{
Jae-Seong Kang ${ }^{1}$, Sung-Han $\mathrm{Oh}^{1}$, Pyung-Goo $\mathrm{Cho}^{2}$ \\ ${ }^{1}$ Department of Neurosurgery, Bundang Jesaeng Hospital, Seongnam, \\ ${ }^{2}$ Department of Neurosurgery, Ajou University Medical Center, Ajou University College of Medicine, Suwon, Republic \\ of Korea
}

Corresponding author:

Pyung-Goo Cho

Department of Neurosurgery, Ajou University Medical Center, Ajou

University College of Medicine, 164

World cup-ro, Yeongtong-gu, Suwon

16499, Republic of Korea

Tel: +82-31-219-7808

Fax: +82-31-210-5236

E-mail: nsdrcpg@ajou.ac.kr

Received: June 9, 2019

Revised: July 26, 2019

Accepted: July 30, 2019

\begin{abstract}
Objective: Zero-profile device (Zero-P) has generally been used as a stand-alone cage in anterior cervical discectomy and fusion (ACDF). However, using Zero-P has been reported to be associated with a high subsidence rate. The present study evaluates the factors that influence the subsidence of ACDF. Methods: Records of a total of 29 patients with degenerative spondylosis resulting in radiculopathy or myelopathy between $C 2$ and $C 7$ who underwent ACDF with Zero-P were retrospectively reviewed. The participants received 1 or 2 level ACDF with Zero-P in our clinic from December, 2011 to December, 2017. A total of 35 treatment levels were included in the analysis. Subsidence was defined when anterior segmental heights decreased by more than $2 \mathrm{~mm}$ during the follow-up period. The patients were divided into the subsidence and non-subsidence groups. The following factors were investigated in relation to the occurrence of subsidence: age, gender, body mass index, diabetes mellitus, cage height, perioperative distraction, segmental lordosis, pain score, fusion grade, anterior/posterior segmental height ratio, and cage distance. Results: Cage subsidence was observed in 15 cases (15/35, 42\%). Cage distance at immediate postoperation was significantly different between the 2 groups; specifically, while the group with subsidence had $2.66 \pm 1.62 \mathrm{~mm}$ distance, the group without subsidence had $1.24 \pm 1.13 \mathrm{~mm}$ distance $(p=0.008)$. Conclusion: This study confirms that the more deeply titanium part is inserted at the anterior edge, the more subsidence occurs. In order to decrease the occurrence of cage subsidence, Zero-P cages should be located the closest possible to the anterior rim of vertebral body at operation.
\end{abstract}

Key Words: Cervical vertebrae; Diskectomy; Spinal fusion

\section{INTRODUCTION}

The method of anterior cervical discectomy and fusion (ACDF) is still performed in most cases and thus remains the golden standard for the treatment of cervical spondylosis, regardless of whether a single segment or multiple segments are involved ${ }^{14,26,27)}$. However, for the autologous tricortical iliac bone transplantation described by Cloward, Smith and Robinson, problems such as morbidity of the donor site and subsidence of the graft site have been reported ${ }^{2,7)}$. To overcome this problem, a method using an interbody cage for ACDF has recently been used, and the reported results were good. The cage is effective in restoring the height of the disc and vertebral column, supporting the anterior region load and preventing the collapse of the graft. The cage is made of a variety of materials, including stainless steel, titanium, carbon fiber, and polyetheretherketone (PEEK). Among these materials, Zero-profile device (Zero-P;
DePuy Synthes Spine, Inc, Raynham, MA, USA), which was approved by the United States Food and Drug Administration in 2008, was generally used as a stand-alone cage in ACDF (Fig. 1). Zero-P can increase the immediate stability of the treated segment even in the absence of an anterior implant, as well as decrease the incidence of postoperative dysphagia and adjacent segments degeneration ${ }^{29)}$. However, using Zero-P

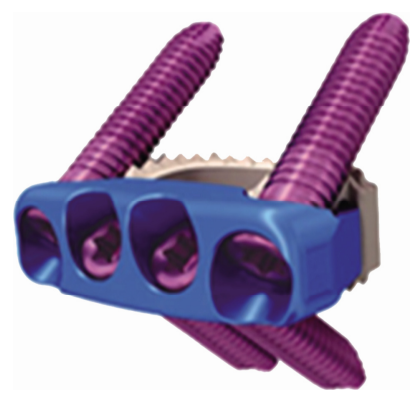

Fig. 1. Zero-profile device (Zero-P; DePuy Synthes Spine, Inc, Raynham, MA, USA) Spacer Compound of polyetheretherketone (PEEK) cage and titanium screw hole part attached to the anterior rim with integrated locking screw fixation. 
has been reported to be associated with a high subsidence rate $(22.8-35.9 \%)^{18,29)}$. The present study aimed to evaluate the risk factors associated with subsidence after ACDF using a Zero-P device.

\section{MATERIALS AND METHODS}

\section{Patients}

From December 2011 to December 2017, a total of 29 selected patients (11 male and 18 female) diagnosed with degenerative spondylosis with radiculopathy or myelopathy between C3 and $\mathrm{C} 7$ were enrolled in this retrospective mono-centric study and underwent ACDF with a Zero-P device. There were 35 operated levels. During that period, 122 patients received 1or 2-level ACDF with Zero-P in our clinic. Indication for surgery was radicular arm pain with/without neck pain or functional/ neurological deficit confirmed by magnetic resonance imaging (MRI) after conservative treatment had failed. A total of 86 patients were excluded because infection, trauma, tumor, and additional posterior cervical surgery cases.

\section{Surgical Procedures}

Each patient was positioned in the neutral supine position. Preoperative fluoroscopy was used to confirm the incision site and adequate visualization of the index level. A transverse skin incision was performed over the affected level on the medial side of the sternocleidomastoid muscle to expose the prevertebral space.

By finger dissection, we developed a plane between the sternocleidomastoid muscle and the carotid artery laterally and the trachea and esophagus medially.

Two hand-held retractors were placed in the operative field, and then the prevertebral fascia was exposed. Under the microscope, the protruded disc compressing the roots or spinal cord was totally removed. Using a high speed drill, and curettage, the superior and inferior vertebral body cartilage end plates were decorticated thorough careful preparation so not as to damage the bony endplate. Sufficient decompression was confirmed by checking the dura mater after that all posterior longitudinal ligament are removed possible. For generous decompression, bilateral uncovertebral joints (UVJs) was resected, even in the asymptomatic side. Venous hemorrhage encountered during resection can always be controlled by cottonoid packing or hemostatic agents. The disc space was distracted, and different sized trial cages were used until an appropriately sized cage was selected. The size and depth of the implant were checked by the fluoroscopy immediately after placement. The cage was positioned so that the Zero-P titanium part was placed on the anterior edge of the upper body and the lower body.
All patients wore a cervical collar for as short as 4 weeks or as long as 4 months depending on the fusion state (probable fusion) identified in the X-ray. Postoperatively early ambulation was encouraged.

\section{Clinical Assessment}

Clinical outcomes were evaluated according to the visual analog scale (VAS) scores and Odom criteria at preoperative $1,3,6$, and 12 months. VAS scores for neck pain and arm pain were measured separately: $0=$ no pain, $10=$ most severe pain imaginable. Odom criteria were rated as follows: excellent=all preoperative symptoms relieved; good=minimal persistence of preoperative symptoms; fair=definite relief of some preoperative symptoms; and poor=symptoms and signs unchanged or exacerbated.

\section{Radiographic Assessment}

Anteroposterior (AP) and lateral plain X-ray images were acquired in all patients immediately after surgery and at 1, 3, 6, and 12 months postoperatively. Anterior segmental height (ASH) posterior segmental height (PSH), cage distance (distance from the front of the vertebrae at the disc level to the front of the cage, $\mathrm{CD}$ ), height ratio (anterior/posterior), perioperative distraction (disc space distance difference between the upper and lower vertebral body before and after surgery), subsidence, bone fusion and the segmental Cobb angle (SCA) were measured using the picture archiving and communication system (PACS) of infinite healthcare. We corrected the length difference according to the magnification by using the front and back length of the vertebra body. The ASH was measured as the distance from the anterior end of the superior plate of the upper vertebra body to the anterior end of the inferior plate of the lower vertebra body. The PSH was measured as the distance from the posterior end of the superior plate of the upper vertebra body to the posterior end of the inferior plate of the lower vertebra body (Fig. 2).

Subsidence was defined as a decrease of ASH by more than $2 \mathrm{~mm}$ on the lateral radiographs during the follow-up period $^{6,13)}$. The SCA was measured as the angle between the superior endplate of the upper vertebra body and the lower endplate of the lower vertebra body. The bone fusion grade was evaluated by using Lenke classification through AP, lateral radiographs. It was graded in the following 4 categories: (1) obvious fusion (Grade A) - Definitely solid with bilateral trabeculated stout fusion masses present; (2) probable fusion (Grade B) - Possibly solid with a unilateral large fusion mass and a contralateral small fusion mass; (3) fusion in question (Grade C) - Probably not solid with a small fusion mass bilaterally; (4) no fusion (Grade D) - Definitely not solid with bone graft resorption or obvious pseudarthrosis bilaterally ${ }^{8}$. 


\section{Statistical Analyses}

All radiographs were evaluated by 2 experienced neurosurgeons blinded to the clinical status of the patients. Statistical analyses were performed using SPSS (version 22.0; SPSS Inc., Chicago, IL, USA). The data were expressed as mean \pm standard deviation (SD) for continuous variables, and number (percentage) for categorical variables. Characteristics between the groups with/without subsidence of cage were compared by the 2 independent samples $t$ test (Mann-Whitney test). A $\chi^{2}$ analysis was applied to find out the frequency difference in the subsidence group. ASH difference and cage distance relations were analyzed using bivariate correlation analysis and regression analysis. The statistical significance was defined as $\mathrm{p}<0.05$.

\section{RESULTS}

\section{Patient Profiles}

A total of 29 patients participated in the present study, and 35 levels were underwent ACDF using Zero-P profile device. Twenty-three patients were 1-level fusions, and 6 patients were 2 level fusions. Table 1 shows patient profiles. The patients
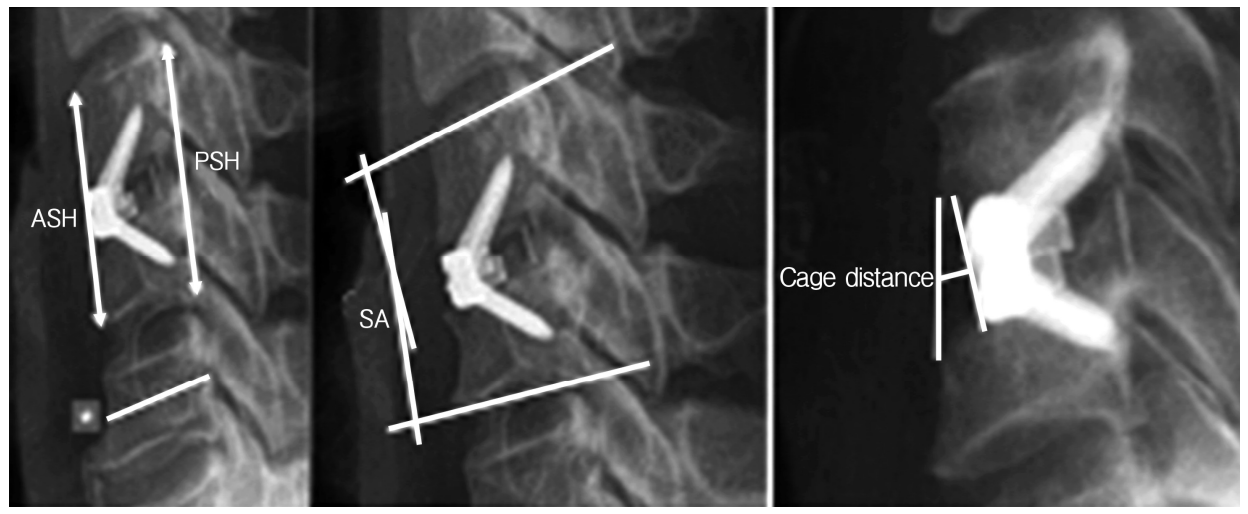

Fig. 2. Anterior segmental height: from the anterior end of the superior plate of the upper vertebra body to the anterior end of the inferior plate of the lower vertebra body. Posterior segmental height: from the posterior end of the superior plate of the upper vertebra body to the posterior end of the inferior plate of the lower vertebra body. Cage distance: from the midpoint of the anterior body line to the midpoint of the anterior border of cage. Segmental angle: the angle between the anterior and posterior ends of the upper vertebra body and the anterior and posterior ends of the lower vertebra body. *According to the magnification using the front and back length of the vertebra body.

Table 1. Analysis of subsidence by patient characteristics

\begin{tabular}{lccc}
\hline & Subsidence group $(\mathrm{n}=15)$ & No subsidence group $(\mathrm{n}=20)$ & $\mathrm{p}$-value \\
\hline Age & $55.5 \pm 11.6$ & $57.2 \pm 14.1$ & 0.696 \\
Gender & 5 & & 0.486 \\
$\quad$ Male & 10 & 11 & \\
$\quad$ Female & & & 0181 \\
Diagnosis & 8 & 15 & \\
$\quad$ CSR & 7 & 5 & \\
CSMR & $24.7 \pm 2.7$ & $25.4 \pm 5.1$ & 0.633 \\
BMl & & & 0.244 \\
DM & 2 & 7 & \\
Illness & 13 & 13 & \\
Normal & $7.2 \pm 1.1$ & $6.7 \pm 0.7$ & 0.133 \\
Cage height $(\mathrm{mm})$ & $2.5 \pm 1.2$ & $1.9 \pm 0.9$ & 0.616 \\
Perioperative distraction $(\mathrm{mm})^{*}$ &
\end{tabular}

The data is presented as number or mean \pm standard deviation.

CSR: cervical spondylotic radiculopathy; CSMR: cervical spondylotic myelo-radiculopathy; BMl: body mass index; DM: diabetes mellitus.

"Disc space distance difference between the upper and lower vertebral body before and after surgery. 
were divided into 2 groups: those with subsidence $(n=15)$ and non-subsidence group $(n=20)$. In 15 levels (42\%) subsidence was observed. There were no differences between the subsidence and non-subsidence groups in patient profiles (age, gender, diagnosis, diabetes mellitus, cage height, and perioperative distraction), body mass index $(24.7 / 25.4 ; \mathrm{p}=0.633)$. The study was approved by the Institutional Review Board (IRB no. DMC 2019-04-003), informed consent was not needed.

\section{Radiological Findings}

Table 2 shows the most frequent site of subsidence (C5/6, $46.6 \%)(\mathrm{p}=0.269)$ and the most frequent period (within 1 months, $53 \%)(\mathrm{p}=0.086)$. Of the 15 levels subsidence, the cage sinking downward was observed in most cases $(13 / 15 ; \mathrm{p}=0.005)$. As can be seen in Table 3, cage distance differed significantly between the 2 groups. Specifically, cage distance in the subsidence group was greater $(2.66 \pm 1.62 \mathrm{~mm}$ vs. $1.24 \pm 1.13 \mathrm{~mm}$ $\mathrm{p}=0.008$ ). Bone fusion, the segmental Cobb angle, height ratio (A/P) did not differ between the 2 groups. Bone fusion grade was more than probable fusion (Grade $\mathrm{C}$ ) at post-op 1 year $\mathrm{X}$-ray in both groups (subsidence group, 14/15; non subsidence group, 20/20), and segmental lordosis tended to decrease 1 year after surgery in both groups. Bivariate correlation analysis between ASH difference 1 year after surgery and cage distance was performed. Spearman correlation coefficients were 0.457 , which had a distinct quantitative linear relationship $(\mathrm{p}=0.019)$ (Table 4). The dependent variable of ASH difference and the independent variable of cage distance had a quantitative linear relationship with the slope of 0.61 and the constant of 0.93

Table 2. Number of treated levels and subsidence period, subsidence direction

\begin{tabular}{lccc}
\hline \hline & $\begin{array}{c}\text { Subsidence } \\
\text { group }\end{array}$ & $\begin{array}{c}\text { No subsidence } \\
\text { group }\end{array}$ & p-value \\
\hline ACDF level & 15 & 20 & 0.269 \\
C3/4 & 2 & 5 & \\
C4/5 & 3 & 1 & \\
C5/6 & 7 & 7 & \\
C6/7 & 3 & 7 & 0.086 \\
Subsidence period & & & \\
Post-op 1 month & $8(53.3 \%)$ & & \\
Post-op 3 months & $2(13.3 \%)$ & & 0.005 \\
Post-op 6 months & $3(20.0 \%)$ & & \\
Post-op 12 months & $2(13.3 \%)$ & & \\
Subsidence direction & & & \\
Upper body & 2 & & \\
Lower body & 13 & & \\
\hline ACDF: anterior cenvical discectomy and fusion; Post-op: postope- \\
rative. \\
Statistically significant difference (p=0.005).
\end{tabular}

( $\mathrm{p}=0.02, \mathrm{p}=0.062$, respectively). When the ASH difference was $2 \mathrm{~mm}$, the cage distance was $1.75 \mathrm{~mm}$ (Fig. 3).

As an example of this study, a 52-year-old female underwent ACDF at cervical spine 5/6. Comparing X-ray immediately after surgery and 1 year after surgery, cage distance was $3 \mathrm{~mm}$ and subsidence was $3.3 \mathrm{~mm}$ (Fig. 4A). On the contrary a 44-year-old female underwent ACDF at cervical spine 5/6. Comparing X-ray immediately after surgery and 1 year after surgery, cage distance was $1 \mathrm{~mm}$ and subsidence did not occur (Fig. 4B).

\section{Surgical Outcomes}

The results are summarized in Table 5. Postoperatively, most

Table 3. Comparison of radiological analysis by period and cage distance

\begin{tabular}{|c|c|c|c|}
\hline & $\begin{array}{l}\text { Subsidence } \\
\text { group }\end{array}$ & $\begin{array}{l}\text { No subsidence } \\
\text { group }\end{array}$ & p-value \\
\hline Cage distance (mm) & $2.66 \pm 1.62$ & $1.24 \pm 1.13$ & 0.008 \\
\hline \multicolumn{4}{|l|}{ Segmental lordosis } \\
\hline Immediate post-op ( $\left.{ }^{\circ}\right)$ & $5.97 \pm 5.11$ & $6.72 \pm 4.15$ & 0.658 \\
\hline Post-op 1 year $\left({ }^{\circ}\right)$ & $4.0 \pm 3.66$ & $4.61 \pm 4.48$ & 0.511 \\
\hline \multicolumn{4}{|l|}{ A/P ratio } \\
\hline Immediate post-op & $1.02 \pm 0.04$ & $0.99 \pm 0.04$ & 0.457 \\
\hline Post-op 1 year & $0.99 \pm 0.05$ & $0.98 \pm 0.05$ & 0.624 \\
\hline \multicolumn{4}{|l|}{ Fusion } \\
\hline Post-op 1 month & & & 0.278 \\
\hline No fusion & 7 & 13 & \\
\hline Fusion in question & 8 & 7 & \\
\hline Post-op 3 months & & & 0.486 \\
\hline Fusion in question & 10 & 11 & \\
\hline Probable fusion & 5 & 9 & \\
\hline \multicolumn{4}{|l|}{ Post-op 6 months } \\
\hline Fusion in question & 4 & 3 & 0.352 \\
\hline Probable fusion & 11 & 15 & \\
\hline Obvious fusion & 0 & 2 & \\
\hline Post-op 1 year & & & 0.159 \\
\hline Fusion in question & 1 & 0 & \\
\hline Probable fusion & 4 & 11 & \\
\hline Obvious fusion & 10 & 9 & \\
\hline
\end{tabular}

The data is presented as number or mean \pm standard deviation. Post-op: postoperative; A/P: anterior segmental height devided by posterior segmental height

Table 4. Bivariate correlation analysis between postoperative 1 year anterior segmental height difference and cage distance

\begin{tabular}{lcc}
\hline \hline & Cage distance & p-value \\
\hline $\begin{array}{c}\text { Post-op } 1 \text { year ASH difference } \\
\text { correlation coefficients }\end{array}$ & 0.457 & 0.019 \\
\hline
\end{tabular}

Post-op: postoperative; ASH: anterior segmental height. 


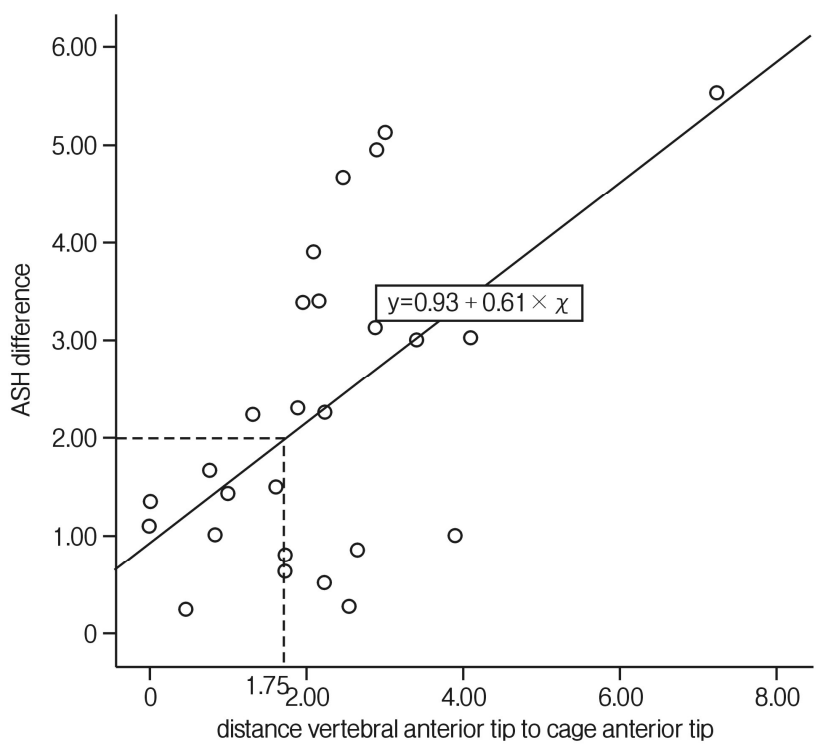

Fig. 3. Dependent variable of the anterior segmental height (ASH) difference and independent variable cage distance have a quantitative linear relationship with the slope of 0.61 and the constant of $0.93(p=$ $0.02, p=0.062$, respectively). When the ASH difference is $2 \mathrm{~mm}$, the cage distance is $1.75 \mathrm{~mm}$.
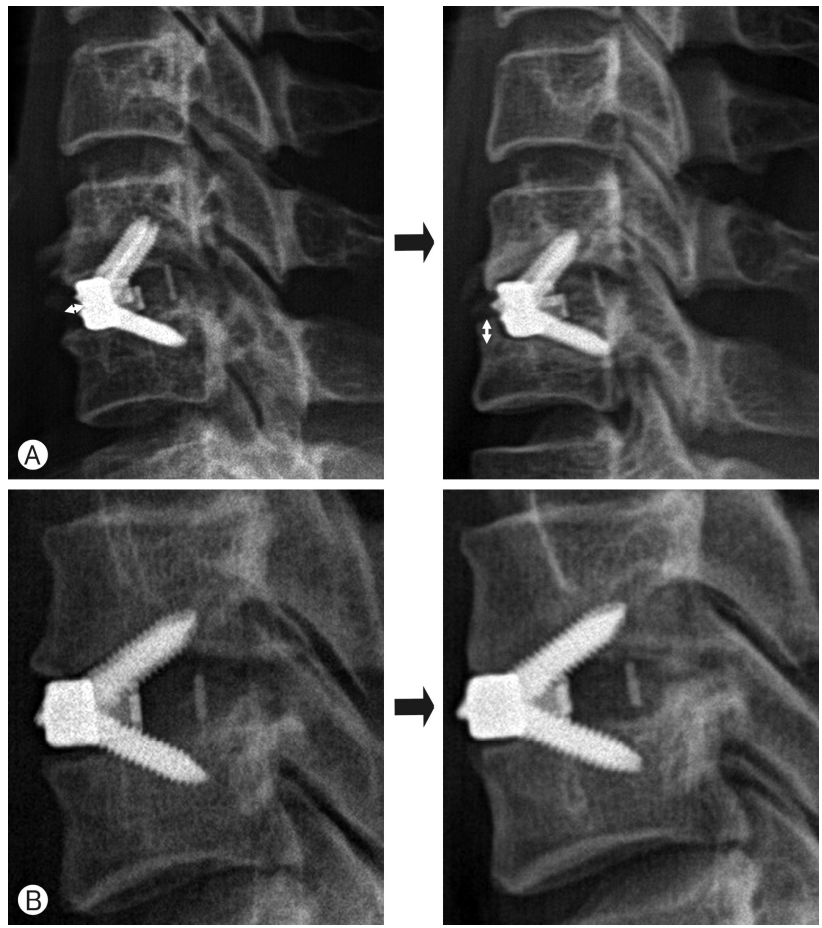

Fig. 4. (A) A 52-year-old female underwent anterior cervical discectomy and fusion at cervical spine 5/6 immediately after surgery (left), 12 months after surgery (right). Cage distance (left) was $3 \mathrm{~mm}$ and subsidence (right) was $3.3 \mathrm{~mm}$. (B) A 44-year-old female underwent anterior cenvical discectomy and fusion at cervical spine 5/6 immediately after surgery (left), 12 months after surgery (right). Cage distance (left) was $1 \mathrm{~mm}$ and subsidence (right) did not occur. patients of the 2 groups were good or excellent according to the Odom's criteria. The most significant improvement was observed at postoperative 1 month in both groups $(\mathrm{p}=0.00)$. At 1 month postoperatively, pain score (VAS, neck) was higher in the subsidence group than in the no subsidence group ( $\mathrm{p}=0.042$ ); furthermore, at 6 month postoperatively, pain score (VAS, arm) was higher in the subsidence group than in the no subsidence group ( $\mathrm{p}=0.028)$; however, no difference between the 2 groups at 1 year later was observed. There was no significant difference between the 2 groups in the Odom's criteria.

\section{DISCUSSION}

The method of ACDF is a widely accepted and safe surgical procedure for the treatment of degenerative cervical spine disease $^{21)}$. The primary purpose is to decompress the spinal cord and nerve roots with restoring cervical alignment. ACDF ensures the height of normal intervertebral foramen through the restoration of intervertebral disc intervals.

ACDF using cages is compared to classical autologous bone graft using iliac bone harvest. It has the advantage of reducing the morbidity of bone grafting. In addition, it can reduce donor site pain and donor site infection and bleeding, as well as reduce operation time and skin scars of donor site. Currently, cage and plate constructs, stand-alone cage, and so on are widely used. The advantages of cage and plate constructs include a higher fusion rate, disc height restoration, as well as better cervical lordosis, and alignment ${ }^{29)}$. However, using cage and plate constructs involves a further risk of hardware-related operative and postoperative complications, such as screw or plate displacement, soft tissue damage, esophageal perforation, and chronic dysphagia, which have been reported particularly if bulky plates are used ${ }^{31)}$. In addition, placing of an oversized plate close to the adjacent level may increase the rate of adjacent level ossification ${ }^{3)}$.

At present, cages are made of various materials, such as PEEK, allograft bone, autograft bone, carbon fiber, and titanium. However, in recent years, PEEK cages are the most commonly used recently $^{28)}$. Among the reasons for this is that titanium or carbon fiber cages have difficulty in judging bone unions using simple X-rays, as well as a poor MRI image quality due to scan artifacts ${ }^{10,12)}$.

In this context, the Zero-P, such as Zero-P with integrated locking screw fixation, which is a compound of PEEK cage and titanium screw hole part attached to the anterior rim, has many advantages. Zero-P has a low risk of dysphagia, plate displacement, soft tissue damage, and esophageal perforation typically caused by a plate; furthermore, PEEK is advantageous for the judging bone unions using simple X-rays and MRI during follow-up period.

The results of an in vitro comparison of Zero-P with cage plate construct showed not only equivalent biomechanical 
stability of the $2^{22)}$, but also that Zero-P system reduces the dysphagia rate and adjacent level ossification rate ${ }^{18)}$. No patients showed dysphagia and adjacent level ossification at 1 year after surgery in this study. However, Zero-P was found to have a higher subsidence rate than cage and plate constructs ${ }^{18)}$. Therefore, in the present study, we sought to find out the reason why subsidence occurs more at Zero-P. Subsidence is known to occur in 30\% to $50 \%$ of cases within 1 year after $\mathrm{ACDF}^{15,23)}$. Since previous studies found no statistically significant differences between subsidence rates of the PEEK (29\%; $25 / 85)$ and allograft groups (28\%; 9/32) $(\mathrm{p}=0.69)^{30)}$, subsidence rate does not seem to be affected by the use of PEEK as spacers in $\mathrm{ACDF}$ using Zero- $\mathrm{P}^{30)}$.

Previous studies on the risk factors of cage subsidence have not achieved consistent results. For instance, while MohammadShahi et al. ${ }^{20)}$ reported that the more inserted the cage was tilted, the more subsidence increased, Lemcke et al. ${ }^{17)}$ reported that the thicker the inserted cage, the more pressure it put on the end plate, and the subsidence increased. Furthermore, Cheng et al. ${ }^{5}$ insisted that the destruction of the subchondral bone of the end plate causes a serious deterioration of the cortical strength, so the degree of curettage on the end plate was an important factor in determining the degree of subsidence. Yang et al. ${ }^{28)}$ reported that the larger the diameter of the cage, the greater the contact area between the end plate and the cage; therefore, the significantly reduced the risk of subsidence and larger intraoperative distraction had a significantly higher risk of subsidence. Also For generous decompression, we need bilateral UVJs resection. About this, Lee et al. $^{16)}$ reported the increase in micro-motion due to excessive uncinate process resection is a major cause of subsidence. In the present study, statistical verification was conducted on

Table 5. Surgical outcomes between the groups

\begin{tabular}{|c|c|c|c|}
\hline & Subsidence group & No subsidence group & $\mathrm{p}$-value \\
\hline \multicolumn{4}{|l|}{ Pain score (VAS) } \\
\hline Pre-op (neck/arm) & $7.6 \pm 0.8 / 5.3 \pm 0.4$ & $7.4 \pm 0.8 / 5.3 \pm 0.6$ & $0.681 / 0.271$ \\
\hline Post-op 1 month & $2.9 \pm 1.0 / 2.3 \pm 0.4$ & $2.2 \pm 0.7 / 2.3 \pm 0.6$ & $0.042^{*} / 0.269 / 0.00^{+}$ \\
\hline Post op 3 months & $1.6 \pm 0.5 / 1.6 \pm 0.4$ & $1.7 \pm 0.5 / 1.5 \pm 0.5$ & $0.615 / 0.134$ \\
\hline Post-op 6 months & $1.6 \pm 0.4 / 1.5 \pm 0.5$ & $1.5 \pm 0.5 / 1.2 \pm 0.4$ & $0.63 / 0.028^{*}$ \\
\hline Post-op 12 months & $1.6 \pm 0.5 / 1.4 \pm 0.5$ & $1.5 \pm 0.5 / 1.2 \pm 0.4$ & $0.58 / 0.110$ \\
\hline \multicolumn{4}{|l|}{ Odom's criteria } \\
\hline Post-op 1 month & & & 0.712 \\
\hline Excellent & 4 & 12 & \\
\hline Good & 10 & 7 & \\
\hline Fair & 1 & 1 & \\
\hline Poor & 0 & 0 & \\
\hline Post-op 3 months & & & 0.845 \\
\hline Excellent & 7 & 14 & \\
\hline Good & 8 & 6 & \\
\hline Fair & 0 & 0 & \\
\hline Poor & 0 & 0 & \\
\hline Post-op 6 months & & & 0.767 \\
\hline Excellent & 9 & 15 & \\
\hline Good & 6 & 5 & \\
\hline Fair & 0 & 0 & \\
\hline Poor & 0 & 0 & \\
\hline Post-op 12 months & & & 0.403 \\
\hline Excellent & 12 & 18 & \\
\hline Good & 3 & 2 & \\
\hline Fair & 0 & 0 & \\
\hline Poor & 0 & 0 & \\
\hline
\end{tabular}

VAS: visual analog scale; Pre-op: preoperative; Post-op: postoperative.

"Confirmed statistical significance. ${ }^{+}$The difference between pre- and post-op 1 month VAS scores in the subsidence group and the no subsidence group. 
several factors considered to be risk factors for cage subsidence. The results showed that cage distance was significantly different between the 2 groups. This confirms that the more deeply cage is inserted at the anterior edge, the more subsidence occurs.

The results of the radiographic analysis of our patients with subsidence showed that subsidence occurred in the titanium region anchored to the anterior part, rather than the middle or posterior part of the vertebral body with PEEK material. Seaman et $\mathrm{al}^{25)}$ reported that titanium cages have a higher subsidence rate than PEEK cages. This is because titanium has a higher stiffness than PEEK and, therefore, gives more pressure to the end plate in contact with titanium.

In the case of subsidence, the titanium part is located inward from the vertebral anterior border. Anderst et al. ${ }^{1)}$ reported that cervical exterior anterior body shows a higher bone mineral density than the cervical central anterior body. Therefore, it appears that subsidence occurs when the titanium part is located in the central anterior part of the vertebral body with a relatively weak intensity. As can be seen in Fig. 3, the more the cage distance is, the more cage subsidence occurs in quantitative correlations. When the ASH difference is $2 \mathrm{~mm}$ diagnosed with subsidence, the cage distance is $1.75 \mathrm{~mm}$, so it is better to maintain the cage distance below $1.75 \mathrm{~mm}$.

In addition, the subsidence occurred mainly in the lower body side. In a review of the literature on the direction of subsidence in ACDF, Kast et al. ${ }^{11)}$ found that subsidence in the anterior lower aspect was the most frequent. Likewise, Grant et al. ${ }^{9)}$ reported that the inferior lumbar endplate was significantly stronger and stiffer than the superior lumbar endplate. In addition, Mabe and Goswami ${ }^{19)}$ reported that the thickest regions are in the anterior region of the inferior endplate, with the posterior region of the superior endplate with the central region being the thinnest area. In the present study, 2 of the 15 cases in the subsidence group had a subsidence toward anterior upwards, and 13 cases developed subsidence toward anterior downward (Fig. 5). Therefore, the lower endplate anterior part of vertebral body has a higher cortical bone mass than the upper endplate anterior part. When inserting the cage between cervical vertebrae, in some patients, the front side of the upper and lower vertebrae side-by-side was not lined. In this case, matching the anterior line of the cage to the anterior line of the lower vertebrae would probably reduce subsidence.

In the present study, pain tended to be slightly higher in the group with subsidence during postoperative period, although the difference did not reach statistical significance. Some authors have argued that subsidence does not have a high clinical significance, as it can improve the cervical kyphosis while maintaining a significant intervertebral disc space ${ }^{4,24)}$. However, in the case of subsidence, it can be deduced that subsidence can eventually result in narrowing of the foramen, nerve root compression, pseudoarthrosis due to cervical instability ${ }^{3,10)}$ and adjacent segment degeneration due to the loss

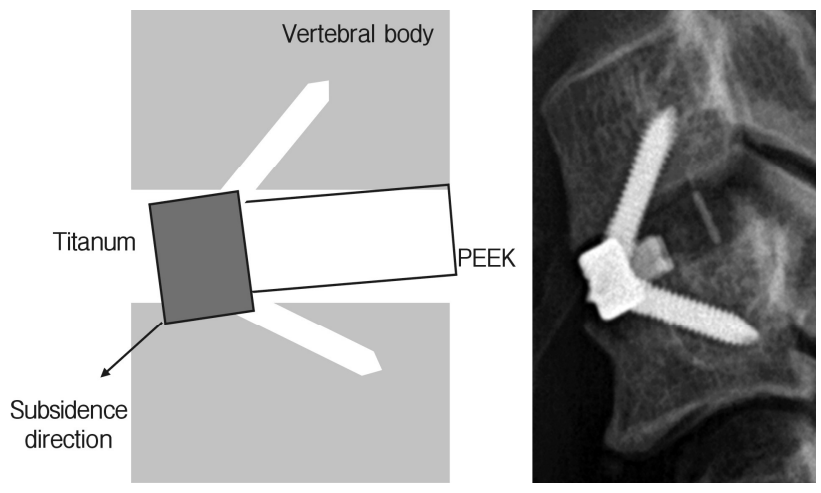

Fig. 5. Subsidence developed towards anterior downwards.

of lordosis ${ }^{12,22)}$. In further research, the clinical significance of the subsidence should be identified through a long-term follow-up study of the correlation between these radiological and clinical results.

The limitations of the present study include the small sample size and the short observation period, which could have biased our results. Therefore, in future studies, larger-scale studies with a longer observation period should be performed.

\section{CONCLUSION}

In the present study, we found no significant differences in the VAS score $s$ and Odom's criteria between the subsidence and the non-subsidence group. To prevent subsidence, Zero-P should be placed in the bony anterior part, and the anterior margin of the titanium part and the anterior margin of the upper plate of the lower vertebral body should maximally coincide.

\section{CONFLICT OF INTEREST}

No potential conflict of interest relevant to this article was reported.

\section{REFERENCES}

1. Anderst WJ, Thorhauer ED, Lee JY, Donaldson WF, Kang JD: Cervical spine bone mineral density as a function of vertebral level and anatomic location. Spine J 11:659-667, 2011

2. Baker ADL. The treatment of certain cervical- spine disorders by anterior removal of the intervertebral disc and interbody fusion. In: Banaszkiewicz PA, Kader DF eds. Classic papers in orthopaedics. London, UK: Springer, 2014, pp293-295

3. Bartels RH, Donk R, van Azn RD: Height of cervical foramina after anterior discectomy and implantation of a carbon fiber cage. J Neurosurg 95:40-42, 2001

4. Bartels RH, Donk RD, Feuth T: Subsidence of stand-alone cervical carbon fiber cages. Neurosurgery 58:502-508; discussion 502-508, 2006 
5. Cheng CC, Ordway NR, Zhang X, Lu YM, Fang H, Fayyazi $\mathrm{AH}$ : Loss of cervical endplate integrity following minimal surface preparation. Spine (Phila Pa 1976) 32:1852-1855, 2007

6. Choi JY, Sung KH: Subsidence after anterior lumbar interbody fusion using paired stand-alone rectangular cages. Eur Spine J 15:16-22, 2006

7. Cloward RB: The anterior approach for removal of ruptured cervical disks. J Neurosurg 15:602-617, 1958

8. Fogel GR, Toohey JS, Neidre A, Brantigan JW: Fusion assessment of posterior lumbar interbody fusion using radiolucent cages: X-ray films and helical computed tomography scans compared with surgical exploration of fusion. Spine J 8:570-577, 2008

9. Grant JP, Oxland TR, Dvorak MF: Mapping the structural properties of the lumbosacral vertebral endplates. Spine (Phila Pa 1976) 26:889-896, 2001

10. Ha SK, Park JY, Kim SH, Lim DJ, Kim SD, Lee SK: Radiologic assessment of subsidence in stand-alone cervical polyetheretherketone (PEEK) cage. J Korean Neurosurg Soc 44:370-374, 2008

11. Kast E, Derakhshani S, Bothmann M, Oberle J: Subsidence after anterior cervical inter-body fusion. A randomized prospective clinical trial. Neurosurg Rev 32:207-214; discussion 214, 2009

12. Katsuura A, Hukuda S, Saruhashi Y, Mori K: Kyphotic malalignment after anterior cervical fusion is one of the factors promoting the degenerative process in adjacent intervertebral levels. Eur Spine J 10:320-324, 2001

13. Kim SY, Yoon $\mathrm{SH}$, Kim D, Oh CH, Oh S: A prospective study with cage-only or cage-with-plate fixation in anterior cervical discectomy and interbody fusion of one and two levels. J Korean Neurosurg Soc 60:691-700, 2017

14. Korinth MC: Treatment of cervical degenerative disc disease current status and trends. Zentralbl Neurochir 69:113-124, 2008

15. Lee CH, Kim KJ, Hyun SJ, Yeom JS, Jahng TA, Kim HJ: Subsidence as of 12 months after single-level anterior cervical interbody fusion. Is it related to clinical outcomes? Acta Neurochir (Wien) 157:1063-1068, 2015

16. Lee SH, Lee JS, Sung SK, Son DW, Lee SW, Song GS: The effect of uncinate process resection on subsidence following anterior cervical discectomy and fusion. J Korean Neurosurg Soc 60:550559, 2017

17. Lemcke J, Al-Zain F, Meier U, Suess O: Polyetheretherketone (PEEK) spacers for anterior cervical fusion: A retrospective comparative effectiveness clinical trial. Open Orthop J 5:348-353, 2011

18. Liu W, Hu L, Wang J, Liu M, Wang X: Comparison of zeroprofile anchored spacer versus plate-cage construct in treatment of cervical spondylosis with regard to clinical outcomes and incidence of major complications: a meta-analysis. Ther Clin Risk Manag 11:1437-1447, 2015

19. Mabe I, Goswami T: Finite element analysis of superior C3 cervical vertebra endplate and cancellous core under static loads. J Biomed Eng Biosci 3:26-33, 2016

20. Mohammad-Shahi MH, Nikolaou VS, Giannitsios D, Ouellet J, Jarzem PF: The effect of angular mismatch between vertebral endplate and vertebral body replacement endplate on implant subsidence. J Spinal Disord Tech 26:268-273, 2013

21. Njoku I, Jr., Alimi M, Leng LZ, Shin BJ, James AR, Bhangoo $S$, et al.: Anterior cervical discectomy and fusion with a zeroprofile integrated plate and spacer device: a clinical and radiological study: Clinical article. J Neurosurg Spine 21:529-537, 2014

22. Oda I, Cunningham BW, Buckley RA, Goebel MJ, Haggerty CJ, Orbegoso CM, et al.: Does spinal kyphotic deformity influence the biomechanical characteristics of the adjacent motion segments? An in vivo animal model. Spine (Phila Pa 1976) 24: 2139-2146, 1999

23. Park JY, Choi KY, Moon BJ, Hur H, Jang JW, Lee JK: Subsidence after single-level anterior cervical fusion with a stand-alone cage. J Clin Neurosci 33:83-88, 2016

24. Schmieder K, Wolzik-Grossmann M, Pechlivanis I, Engelhardt M, Scholz M, Harders A: Subsidence of the wing titanium cage after anterior cervical interbody fusion: 2-year follow-up study. J Neurosurg Spine 4:447-453, 2006

25. Seaman S, Kerezoudis P, Bydon M, Torner JC, Hitchon PW: Titanium vs. polyetheretherketone (PEEK) interbody fusion: Meta-analysis and review of the literature. J Clin Neurosci 44: 23-29, 2017

26. Tracy JA, Bartleson JD: Cervical spondylotic myelopathy. Neurologist 16:176-187, 2010

27. Vanek P, Bradac O, DeLacy P, Saur K, Belsan T, Benes V: Comparison of 3 fusion techniques in the treatment of the degenerative cervical spine disease. Is stand-alone autograft really the "gold standard?": prospective study with 2-year follow-up. Spine (Phila Pa 1976) 37:1645-1651, 2012

28. Yang JJ, Yu CH, Chang BS, Yeom JS, Lee JH, Lee CK: Subsidence and nonunion after anterior cervical interbody fusion using a stand-alone polyetheretherketone (PEEK) cage. Clin Orthop Surg 3:16-23, 2011

29. Yin M, Ma J, Huang Q, Xia Y, Shen Q, Zhao C, et al.: The new Zero-P implant can effectively reduce the risk of postoperative dysphagia and complications compared with the traditional anterior cage and plate: a systematic review and meta-analysis. BMC Musculoskelet Disord 17:430, 2016

30. Yson SC, Sembrano JN, Santos ER: Comparison of allograft and polyetheretherketone (PEEK) cage subsidence rates in anterior cervical discectomy and fusion (ACDF). J Clin Neurosci 38:118121,2017

31. Zhang L, Wang J, Tao Y, Feng X, Yang J, Zhang S: Outcome evaluation of zero-profile implant compared with an anterior plate and cage used in anterior cervical discectomy and fusion: A two-year follow-up study. Turk Neurosurg 26:416-422, 2016 